\title{
Cyclodextrins Increase the Cytotoxicity of Curcumin Derivatives in Osteosarcoma Cell Culture
}

\author{
LAURA STOICA ${ }^{1}$, ELENA CARMEN COTRUTZ ${ }^{1 *}$, CRISTIAN ONISOR ${ }^{2 *}$, \\ CARMEN TIUTIUCA ${ }^{2}$, PAVEL ONOFREI ${ }^{1}$, CAMELIA ANA GRIGORE ${ }^{2}$, \\ ANA EMANUELA BOTEZ ${ }^{1}$, VASILE BOGDAN GRECU ${ }^{1}$, DOINITA TEMELIE OLINICI ${ }^{1}$, \\ DOINA CARINA VOINESCU ${ }^{2}$, BOGDAN ALEXANDRU STOICA ${ }^{3}$ \\ ${ }^{1}$ Grigore T. Popa University of Medicine and Pharmacy, Faculty of Medicine, Department of Cell and Molecular Biology, \\ Morphofunctional Sciences (II), 16 Universităţii Str., 700115, Iasi, Romania \\ ${ }^{2}$ Dunarea de Jos, University of Medicine and Pharmacy, 47 Domneasca Str., 800008, Galati, Romania \\ ${ }^{3}$ Grigore T. Popa University of Medicine and Pharmacy, Faculty of Medicine, Department of Biochemistry, \\ Morphofunctional Sciences (II), 16 Universității Str., 700115, Iasi, Romania
}

\begin{abstract}
Cyclodextrins (CDs), a group of oligosaccharides formed by glucose units bound togetherin a ring, showed a promising ability to form supramolecular complexes with drug molecules and improved theirphysicochemical properties without any molecular modifications. On the other hand, a large number of synthetic curcumin derivatives showed promising anticancer results on malignant cell cultures in recent years. This study presents the advantages and limitations of CDs (potential enhancers of solubility and stability) when are used together with a series of curcumin complexes. All the CD-curcumin complex mixtures were tested as potential anticancer agents on a human osteosarcoma cell culture. A variant of beta-cyclodextrin (monochlorotriazinyl- $\beta$-cyclodextrin sodium salt) was found to exhibit the best results in terms of solubility and cytotoxicity enhancements. The results(expressed as inhibitory concentrations for $50 \%$ cell viability - IC $C_{50}$ ) showed significant improvements for manganese and cooper curcumin complexes and had no effects for boron and thorium complexes.
\end{abstract}

Keywords: cyclodextrins, solubility, curcumin complexes, anticancer effects

\section{Introduction}

Chemically, natural CDs are cyclic oligosaccharides produced by enzymatic degradation of starch [1].They are constituted of 6,7 and 8 glucopyranose units, corresponding to $\alpha, \beta$, and $\Upsilon$-cyclodextrin, each connected by 1,4 hydroxyl linkages. The CDs have a shape of a truncated cone structure, in which the internal cavity diameter increases with the number of glucopyranose units, from 5.7 to 7.8 and 9.5 $\AA$ [2].The CDs have a special structure, being hydrophilic on the external faces of CDs, and the internal cavity is relatively apolar. The central cavity of CDs, being composed of glucose backbone residues, is lipophilic in aqueous solutions and can reversibly entrap apolar molecules (or part of molecules), leading to an inclusion complex[3,4].Nevertheless, this special conformationis able to generate new physicochemical characteristics for the inclusion complexes, among which the water solubility of the guest molecule is increased and as a consequence its bioavailability[5]. Since the first discover in 1891, more than35 different drugs are currently marketed as solid or solution-based CD complex formulations [6,7]. In these pharmaceutical products, CDs are mainly used as complexing agents to increase theaqueous solubility of poorly water-soluble drugs, to increase their bioavailability and stability [8,9]. In addition, CDs can be used to reduce or prevent gastrointestinal and ocular irritation, to prevent drug-drug or drug-additive interactions, to reduce or eliminate unpleasant smells or tastes $[10,11]$. The aim of the present study was to analyze the therapeutic potential of some curcumin complexes as potential anticancer agents in association with different variants of CDs. For this purpose,several types of CDs were used to increase the solubility of different complexes of curcumin.

*email:cotrutz@yahoo.com; cristi.onisor@gmail.com,tiutiuca_carmen@yahoo.com 
Curcumin is a promising antitumoral and antioxidant agent,being considered a plurifactorial therapeutic agent, but it cannot be marketed in the pharmaceutical field because of its poor solubility and bioavailability.In the last three decades,more than 15000 publications were available on the Pubmeddatabase having as a central subject curcumin and/or derivative of curcumin but a final therapeutic solution it is still expected. The present study was focused on the potential cytostatic effects for some complexes of curcumin and mitocurcumin (which contains triphenyl-phosphonium radicals in order to increase the mitochondrial accumulation) [12-14], in the presence and absence of various CDs. The inorganic part of the complexes consisted in different metals (manganese, copper, thorium) and nemetals (boron).

\section{Materials and methods}

\subsection{Chemicals}

Curcumin (C), n-butyl-triphenyl-phosphonium bromide, sodium hydride, manganese (II) acetate, copper (II)acetate, thorium (IV) nitrate and boric acid were obtained from Sigma-Aldrich (St. Louis, USA) and used without any further purification.

\subsection{Synthesis of curcumin complexes}

Manganese-curcumin complex (Mn-C) synthesis was performed as already described [12].Manganese acetate $\left(1.65 \mathrm{~g}\right.$ dissolved in $10 \mathrm{~mL}$ absolute ethanol) was heated to $60^{\circ} \mathrm{C}$ under nitrogen atmosphere. Curcumin $(2.4 \mathrm{~g}$ in $150 \mathrm{~mL}$ absolute ethanol) was added dropwise and the reaction mixture was refluxed for $3 \mathrm{~h}$. The obtained solid was filtered, washed with cold ethanol and dried at the desiccator. About $1.5 \mathrm{~g}$ of manganese (II)-curcumin complex (red-brown powder) were obtained (Figure 1).



Figure 1. Divalent manganese curcumin complex $(\mathrm{Mn}-\mathrm{C})[12]$

Manganese-curcumin-butyl-triphenyl-phosphonium complex (Mn-C-TPP) (Figure 2) was performed using the procedures already described[13]. A solution of $\mathrm{Mn}-\mathrm{C}$ (854 $\mathrm{mg}, 1.76 \mathrm{mmol})$ in dry N,N-dimethylformamide $(6 \mathrm{~mL})$ was combined with $\mathrm{NaH}(84 \mathrm{mg}, 2.1 \mathrm{mmol})$ and stirred for 90 min at room temperature. A solution of bromide-butyl-triphenyl-phosphonium bromide in dry dimethylformamide $(1.76 \mathrm{mmol}=842 \mathrm{mg}$ in $6 \mathrm{~mL} \mathrm{DMF})$ was added dropwise. The resulting mixture was stirred for $48 \mathrm{~h}$ at room temperature. The final stages aimed at purification, through consecutive filtrations and washes with cold distilled water. After filtration, washing and drying procedures, about $0.5 \mathrm{~g}$ of a brown compound was obtained and the final product was kept at room temperature in an inert atmosphere of nitrogen and protected from light.

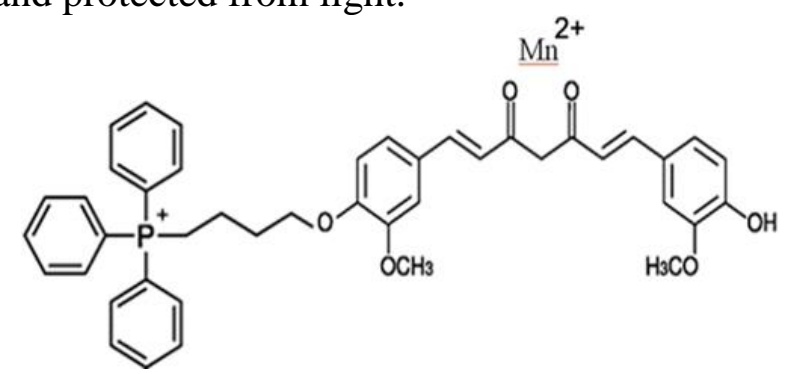

Figure 2. Curcumin complex divalent manganese with a butyl triphenyl phosphonium radical (Mn-C-TPP)[13] 
Copper-curcumin synthesis was performed as already described by Pi et al.[16].Briefly, copper (II) acetate $3 \mathrm{H} 20(0.20 \mathrm{mmol})$ and curcumin $(0.1 \mathrm{mmol})$ were dissolved in $10 \mathrm{~mL}$ ethyl acetate. The reaction mixture was stirred at $80^{\circ} \mathrm{C}$ for $3 \mathrm{~h}$. The coper complex was precipitated from the resulting solution after cooling at $12^{\circ} \mathrm{C}$ and collected by vacuum filtration. The product (Figure 3) was washed with dichloromethane $(30 \mathrm{~mL} \times 3)$, chloroform $(30 \mathrm{~mL} \times 3)$ and ethyl alcohol (30 mL x 2), respectively. A gray-green solid was obtained.

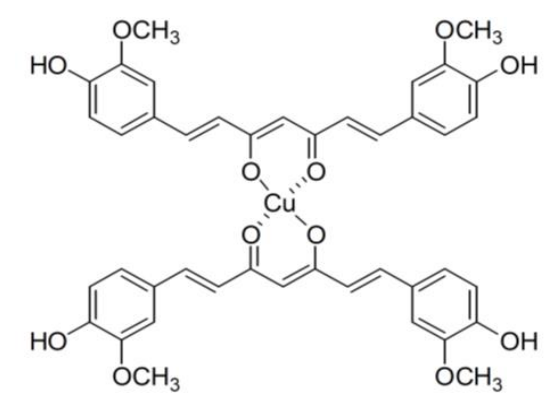

Figure 3.Structure of curcumin complex with copper divalent ions $-\mathrm{Cu}^{2+}(\mathrm{C})_{2}$ according to John et al. [17]

Thorium-curcumin complex (Figure 4) was performed using a modified procedure described by Vajragupta et al. [12].Thorium nitrate was the metal source for the complexation, by direct coupling under alkaline conditions and using the appropriate solvent (alcohol and DMSO), the complexation being made under the common conditions for curcumin complexes.

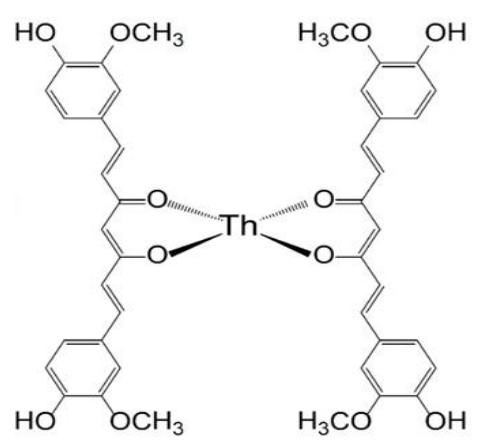

Figure 4. The proposed structure of thorium- curcumin complex $\mathrm{Th}(\mathrm{C})_{2}$

Two curcumin complexes with boron weresynthetized as already described in literature [18]. For synthesis, two slightly modified protocols were used that generate both a complex of two boron curcumin molecules (rosocyanin or $\mathrm{B}(\mathrm{C})_{2}$ - Figure 5) and a curcumin-boron-oxalic acid complex (rubocurcumin or $\mathrm{B}(\mathrm{C}) \mathrm{Ox}$ - Figure 6). Both complexes were purified and dissolved in DMSO as stock solutions.<smiles>COc1cc(/C=C/C2=C(C)C(/C=C/c3ccc(O)c(O)c3)O[PH]3(OC(/C=C/c4ccc(O)c(O)c4)=C(C)C(O)O3)O2)ccc1O</smiles>

Figure 5.The proposed structure for curcumin complex with boron - rosocyanin or $\mathrm{B}(\mathrm{C})_{2}[18]$ 


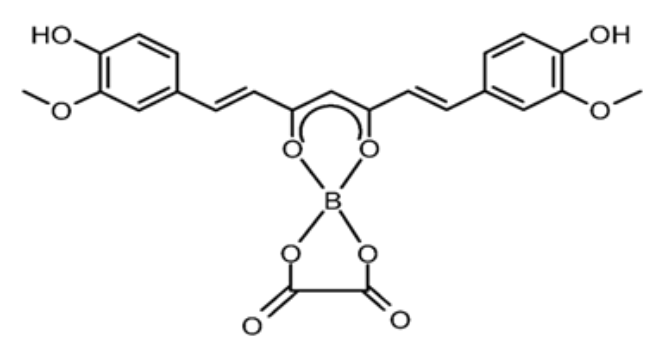

Figure 6.The proposed structure for curcumin complex with boron and oxalic acid - rubocurcumin or $\mathrm{B}(\mathrm{C}) \mathrm{Ox}[18]$

\subsection{Solubility tests}

Ultrasonication was used to initiate the formation of inclusion complexes (titanium rod ultrasonicator, Hielscher UP400St, Germany, $\mathrm{t}=2 \mathrm{~min}$ in $2 \mathrm{~s}$ pulses).

All the solubility tests were conducted according to literature data,using a spectrophotometric protocol $[13,15]$. All the calibration curves were obtained by spectrophotometric analysis of solutions, at appropriate wavelengths. Samples of complexes in quantities exceeding their solubility were ultrasonicated for $2 \mathrm{~min}$ and shaken at the room temperature for $72 \mathrm{~h}$. After filtration using $0.22 \mu \mathrm{M}$ Millipore filters, all the saturated solutions were spectrophotometrically analysed. For all curcumin complexes, several cyclodextrins were tested (simple $\alpha, \beta$ and $\gamma$ cyclodextrins,2-hydroxy-propyl- $\beta$ cyclodextrin, polymer-coupled $\beta$-cyclodextrin and monochlorotriazinyl- $\beta$-cyclodextrin) and the best results were obtained by using monochlorotriazinyl- $\beta$-cyclodextrin (MCT- $\beta$-CD) (Figure 7).

The final protocol of making the inclusion complexes with CDs included:

- 10 min of fine grinding for the mixtures (2:1 molar ratio - MCT- $\beta$-CD:curcumin complexes)

- DMSO dropwise addition and 10 min of grinding

- ultrasonication in pulses of $2 \mathrm{~s}$ for 2 min without exceeding $50^{\circ} \mathrm{C}$

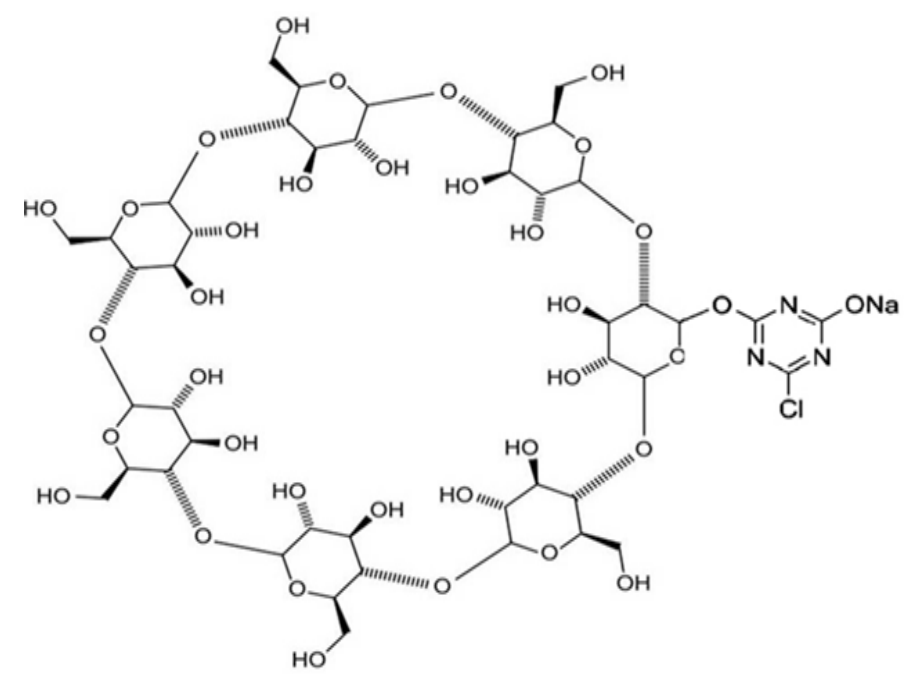

Figure 7. The structure of MCT-beta-cyclodextrin (monochlorotriazinyl- $\beta$-cyclodextrin sodium salt) used to increase the solubility of the compounds in the study

\subsection{Testing of cytostatic properties}

All curcumin complexes, were tested at various concentrations $(1-100 \mu \mathrm{M})$ on a malignant cell line, HOS (human osteosarcoma cells). The cell lines were purchased from Cell Lines Services CLS (Eppelheim, Germany). Cells were grown in Dulbecco's Modified Eagle (DMEM) medium, supplemented with $10 \%$ FBS, $2 \%$ sodium pyruvate, nonessential amino acids $(2 \mathrm{mM})$, penicillin (100U 
/ $\mathrm{mL})$, streptomycin $(100 \mathrm{ng} / \mathrm{mL})$ and glutamine $(4 \mathrm{mM})$. After obtaining a confluence of about $70 \%$ at $37^{\circ} \mathrm{C}$ in a humidified atmosphere with $5 \% \mathrm{CO}_{2}$ and $95 \%$ air, the cells were detached with trypsinEDTA, counted and placed in a 96-well plate at a density of $962 \times 10^{4}$ cells / well.

\subsection{Viability tests}

The cell viability assay was performed using the MTT method, as described in the literature [19]. After seeding the cells in the 96 wells with treated cell tissues and adhering overnight, the cell lines and compounds of various concentrations were contacted for $48 \mathrm{~h}$. An MTT solution was added to each well so that a concentration of $0.3 \mathrm{mg} / \mathrm{mL}$ MTT was obtained. Cells were incubated with MTT for 4 hours at a temperature of $37^{\circ} \mathrm{C}$. After removal of the supernatant, $200 \mu \mathrm{L}$ DMSO was added and the absorbance was read at $570 \mathrm{~nm}$. All samples were performed in triplicate. The method is based on the ability of succinate dehydrogenase from living cell mitochondria to reduce soluble tetrazolium salts in insoluble formazan, stain in red, compare to dead cells where this enzymatic function is no longer present.All assays were performed in triplicate.

\section{Results and discussions}

The curcumin complexes with $\mathrm{Mn}, \mathrm{Cu}, \mathrm{B}, \mathrm{Th}$, as well as the Mn-C-Tpp derivative were prepared and purified for osteosarcoma cell line (HOS) testing.

After the addition of MCT- $\beta-C D(2: 1$ molar ratio) in DMSO, the solubility of the tested compounds was significantly increased. MCT- $\beta-C D$ alone showed no toxicity up to $1000 \mu \mathrm{M}$ when used in cell cultures.

Following HOS osteosarcoma cell line testing, it was observed that only some of the curcumin derivatives exhibit cytostatic activity (Table 1).

Table 1. $\mathrm{IC}_{50}$ values for curcumin derivatives evaluated with MTT assay on human osteosarcoma cells (HOS) after $24 \mathrm{~h}$ exposure-consistent with literature data: ${ }^{\mathrm{a}}[20,21],{ }^{\mathrm{b}}[13],{ }^{\mathrm{c}}[18]$

\begin{tabular}{|c|c|c|}
\hline \multirow{2}{*}{ Compound } & \multicolumn{2}{|c|}{$\mathrm{IC}_{50} \mu \mathrm{M}$} \\
\hline & without MCT- $\beta$-CD & with MCT- $\beta$-CD 1:2 \\
\hline Curcumin (C) & $59 \pm 3^{\mathrm{a}}$ & $57 \pm 3$ \\
\hline Mn-C & not soluble $^{b}$ & $18.5 \pm 1.2$ \\
\hline Mn-C-TPP & not soluble $^{\mathrm{b}}$ & $19.6 \pm 0.4$ \\
\hline $\mathrm{Cu}(\mathrm{C})_{2}$ & $29.1 \pm 4.2^{\mathrm{a}}$ & $19.6 \pm 3.5$ \\
\hline $\operatorname{Th}(\mathbf{C})_{2}$ & $>100$ & $>100$ \\
\hline $\mathrm{B}(\mathrm{C})_{2}$ & not stable ${ }^{c}$ & not stable \\
\hline $\mathbf{B}(\mathrm{C}) \mathrm{Ox}$ & not stable ${ }^{\mathrm{c}}$ & not stable \\
\hline
\end{tabular}

Current results suggested that the manganese derivatives of curcumin have an anti-proliferative effect (which is superior to simple curcumin) but only if the compounds are complexed with MCT- $\beta$ CD.

Since the cooper-curcumin complex has an acceptable solubility, this complex was able to be tested alone and compared with the CDs inclusion complex. The presence of beta-cyclodextrin amplified the cytotoxic effects of the divalent copper-curcumin combination (Figure 8). 




Figure 8.The $\mathrm{IC}_{50}$ value $(\mu \mathrm{M})$ in the presence of cyclodextrin is significantly lower in comparison with curcumin-copper complex without cyclodextrin $(\mathrm{p}<0.05)$

Regarding $\mathrm{Cu}(\mathrm{Cur})_{2}$ complex, the results described above are consistent with the literature data $[17,22]$. One possible explanation may consider the increase of solubility due to the DMSO solvent and MCT- $\beta$-CD addition. Another possible reason could be by improving of the stability of the active compounds. Although one of the main reasons for studying the organo-metallic complexes of curcumin is linked to the stability of the molecule and the bioavailability, the $\mathrm{Cu}(\mathrm{Cur})_{2}$ complex could be instable in culture media. This degree of instability, can be reduced by cyclodextrin complexation a well-known variant in pharmacology [23].

For the manganese-curcumin complexes, the weak solubility in aqueous media was already demonstrated [13]. Our current results suggested that the main reason for the lack of cytotoxicity is poor solubility, which can be overcome by the addition of $\beta$-cyclodextrins.

Although the combination of curcumin and tetravalent ions of a radioactive metal - thorium (Figure 4)has been successfully achieved and this complex appears to have good chemical stability, there is no obvious antitumor activity. The most likely explanation is related to the poor solubility of the obtained compounds, even in the presence of CDs. However, future research must verify some other curcumin sensitive malignant cell lines, like glioblastoma [24].

Following the mentioned synthesis protocols, the two complexes of curcumin with boron (Figure 5,6) were obtained, purified and prepared for testing on cell lines. As other complexes described in this paper, boron complexes were also solubilized in DMSO in the presence of beta-cyclodextrin and by ultrasonication. After 24 hours of contact of the complex at various concentrations $(1-100 \mu \mathrm{M})$ with the HOS cell line, a precipitation of the compounds used in the culture medium was observed, which suggested a lack of stability in culture media, even in the presence of CDs.

\section{Conclusions}

According to the solubility results, the best method for a significant increase of the dissolved curcumin complexes was a combination of solvent (DMSO), chemical enhancements (MCT- $\beta$-CD) and physical interventions (ultrasonication). Using these improvements, the cytotoxic effects of manganese (II)-curcumin complex, triphenylphosphonium-curcumin-manganese (II) complex and cooper (II) - curcumin complex became significantly better than the simple curcumin solutions. CDs seems to be the most important part in this equation, and the best results were obtained with the variant MCT- $\beta$-CD. It is noteworthy that some compounds used in this study were not influenced by any of 
the methods (including CD complexation): the solubility of thorium-curcumin complex remains almost the same and also the stability of boron-curcumin complexes was not improved. However, for the CDs-curcumin-metal complexes with improved biological properties, further studies are needed for demonstrating another potential important effects: time stability and better biodisponibility.

\section{References}

1.LOFTSSON, T., DUCHENE, D., Int. J. Pharm.,329, 2007, p.5.

2.CARNEIRO, S.B., DUARTE, F.I.C., HEIMFARTH, L., QUINTANS, J.S.,QUINTANS-JÚNIOR, L.J., DA VEIGA JÚNIOR, V.F., DE LIMA, A.A., Int. J. Mol. Sci.,20(3), 2019, p.642.

3.UEKAMA, K., HIRAYAMA, F., IRIE, T., Chem. Rev., 98, 1998, p. 2052.

4.FRÖMMING, K.H., SZEJTLI, J., Kluwer Academic Publishers, Dordrecht, 1994.

5.DUCHÊNE, D., BOCHOT, A., J. Ijpharm,,514,2016, p.60.

6.LOFTSSON, T., BREWSTER, M., MASSON, M., Am. J. Drug Deliv. 2, 2004, p. 268.

7.DAVIS, M.E., BREWSTER, M., Nat. Rev., Drug Discov.,3,2004, p. 1029.

8.AVDEEF, A, BENDELS, S., TSINMAN, O., TSINMAN, K., KANSY, M., Pharm. Res. 24, 2007, p. 541.

9.KIM, C., PARK, J., Am. J. Drug Deliv. 2, 2004, p. 116.

10.LOFTSSON, T., JARHO, P., MASSON, M, JARVINEN,T., Expert Opin. Drug Deliv.,2 2005, p. 342.

11.SZEJTLI, J.,SZENTE, L., Eur. J. Pharm. Biopharm.,61, 2005, p. 119.

12.VAJRAGUPTA, O, BOONCHOON, P., WATANABE, H., Free Radic. Biol. Med., 35, nr.12, 2003, p. 1636.

13.STOICA, B.A., PETREUS, T., CIOANCA, O., HANCIANU, M., Farmacia, 63, nr. 6, 2015,p. 886.

14.STOICA, L., STOICA, B. A., OLINICI, D., ONOFREI, P., BOTEZ, A.E., COTRUTZ, C.E., RJME, 59, nr. 1,2018, p. 67.

15.HIGUCHI, T., CONNORS, K., Adv. Anal. Chem. Instrum.,4, 1965, p.117-122.

16.PI, Z., WANG, J., JIANG, B., Mater. Sci. Eng. C. Mater. Biol. Appl., 46, 2015, p.569.

17.JOHN, V.D., KUTTAN, G., KRISHNANKUTTY, K.,J. Exp. Clin. Cancer Res., 21, nr. 2, 2002,p. 221.

18.SPICER, G.S., STRICKLAND, J.D.H., Journal of the Chemical Society (Resumed), 1952,p.4651.

19.CARMICHAEL, J.G.W., GAZDAR, A.F., Cancer Res., 47, nr.4, 1987,p.944.

20.DHULE, S.S., PENFORNIS, P., FRAZIER, T., Nanomedicine, 8, nr.4,2012,p. 447.

21.JIN, S., XU, H.G., SHEN, J.N., Orthop. Surg., 2, 2009,p. 148.

22.JOHN, V.D., KRISHNANKUTTY, K., Transition Metal Chemistry,30, nr. 2, 2005,p. 230.

23.KURKOV, S.V., LOFTSSON, T., Int. J. Pharm.,453, nr.1,2013, p. 168.

24.AlEXANDRU, O., GEORGESCU, A.M., DRAGOI, A., CIUREA, M.E., TAISESCU, C.I., TATARANU, L.G., BRINDUSA, C., BOLDEANU, M.V., PURCARU, S.O., SILOSI, C.A., DEMETRIAN, A., DRICU, A., Rev. Chim., 70(1), 2019, 112-117

$\overline{\text { Manuscript received: } 26.02 .2020}$ 